\title{
Efficient Cationic Ring-Opening Polymerization of Diverse Cyclic Imino Ethers: Unexpected Copolymerization Behavior
}

\author{
Hanneke M. L. Lambermont-Thijs, ${ }^{\dagger}$ Martin W. M. Fijten, ${ }^{\dagger}$ A. J. (Ton) van der Linden, ${ }^{\dagger}$ Bart M. van Lankvelt, ${ }^{\dagger}$ \\ Meta M. Bloksma, ${ }^{+,+, \S}$ Ulrich S. Schubert, ${ }^{*,+,+,}$ and Richard Hoogenboom ${ }^{*,+, \perp}$ \\ ${ }^{\dagger}$ Laboratory of Macromolecular Chemistry and Nanoscience, Eindhoven University of Technology, Den Dolech 2, 5612AZ Eindhoven, \\ The Netherlands \\ ${ }^{\ddagger}$ Laboratory of Organic and Macromolecular Chemistry (IOMC) and Jena Center for Soft Matter (JCSM), Friedrich-Schiller University \\ Jena, Humboldtstrasse 10, 07743 Jena, Germany \\ ${ }^{\S}$ Dutch Polymer Institute (DPI), P.O. Box 902, 5600 AX Eindhoven, The Netherlands \\ ${ }^{\perp}$ Supramolecular Chemistry Group, Department of Organic Chemistry, Ghent University, Krijgslaan 281 S4, B-9000, Ghent, Belgium
}

ABSTRACT: The recently developed fast microwave-assisted cationic ring-opening polymerization procedure for 2-oxazolines seems to be ideally suited for slower polymerizing cyclic imino ether monomers. In this study we report the effect of the cyclic imino ether structure on the polymerization rate under exactly the same microwave-assisted conditions revealing that indeed less reactive cyclic imino ethers, including 2-oxazines as well as 4- and 5-substituted 2-oxazolines, can be polymerized to at least $50 \%$ conversion for the slowest monomer, namely 5-methyl-2-butyl-2-oxazoline, within $10 \mathrm{~h}$. In addition, the copolymerization behavior of 4-ethyl-2-butyl-2-oxazoline with 2-methyl-2-oxazoline and 2-phenyl-2-oxazoline unexpectedly revealed faster incorporation of the less reactive 4-ethyl-2-butyl-2oxazoline monomer compared to 2-phenyl-2-oxazoline due to the increased bulk of the latter monomer amplifying the sterical hindrance for polymerization onto the 4-ethyl-2-butyl-2-oxazolinium propagating species.

\section{INTRODUCTION}

The cationic ring-opening polymerization (CROP) of 2-oxazoline and 2-oxazine cyclic imino ethers was first reported by Litt and co-workers in a patent application in $1965 .{ }^{1}$ Shortly after the (living) polymerization of 2-oxazolines using various initiating systems was reported by four independent research groups. ${ }^{2-5}$ The first scientific publication on 2-oxazine polymerization also appeared in this early days of cyclic imino ether polymerization. ${ }^{6}$ The first CROP of chiral 4- and 5-substituted-2-oxazolines was reported almost a decade later. ${ }^{7,8}$

Despite these early reports on the CROP of 2-oxazines and 4and 5- substituted 2-oxazolines, the major interest of polymer scientists has been on the CROP of 2-oxazolines, ${ }^{9,10}$ resulting in their exploration for various applications, including biomedical materials, advanced (hierarchical) self-assembly and thermoresponsive properties. ${ }^{11-13}$ The properties and applications of poly(cyclic imino ether)s beyond the common poly(2-oxazoline)s have hardly been explored; although there is no reason to assume less application potential or property tuning by copolymerization as well as side-chain variation of the other poly(cyclic imino ether)s. The only rationale for the tremendously lower attention for these other poly(cyclic imino ether)s might be their relatively slow polymerization ranging from tens of hours to multiple days.

Recently we have introduced a microwave-assisted protocol to accelerate the CROP of 2-oxazolines from multiple hours to minutes, ${ }^{14,15}$ which has been adopted by several research other

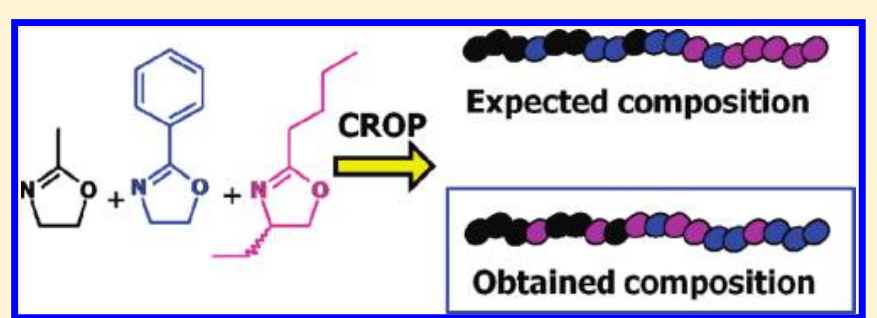

groups. ${ }^{16,17}$ Importantly, a detailed comparison between microwave heating and thermal heating revealed that the observed acceleration is solely due to the increased reaction temperature for both 2-ethyl-2-oxazoline and 2-phenyl-2-oxazoline). ${ }^{14,18}$ Nonetheless, this accelerated CROP protocol seems to be ideally suited for slower polymerizing cyclic imino ether monomers as was indeed demonstrated for 2-phenyl-2-oxazine by Ritter ${ }^{19}$ and for 4-ethyl-2-butyl-2-oxazoline by our group. ${ }^{20}$ However, the effect of cyclic imino ether structure on the polymerization rate has never been evaluated for a wider range of structures; in particular not under exactly the same conditions. Therefore, this study aims to address the potential of the fast microwave-assisted CROP protocol for various cyclic imino ethers (Scheme 1), including very slow polymerizing monomers, by comparison of their polymerization behavior. In addition, the copolymerization behavior of 4-ethyl-2-butyl-2-oxazoline with 2-methyl-2-oxazoline and/or 2-phenyl-2-oxazoline will be discussed.

\section{EXPERIMENTAL DETAILS}

Materials. Solvents were purchased from Biosolve. Acetonitrile was dried over molecular sieves (size $3 \AA$ ) before usage as polymerization

Received: February 23, 2011

Revised: April 4, 2011

Published: May 11, 2011 
Scheme 1. Schematic Representation of the Structures of the Investigated Cyclic Imino Ethers (Left) and the General Mechanism of the Cationic Ring-Opening Polymerization of Cyclic Imino Ethers (Right)

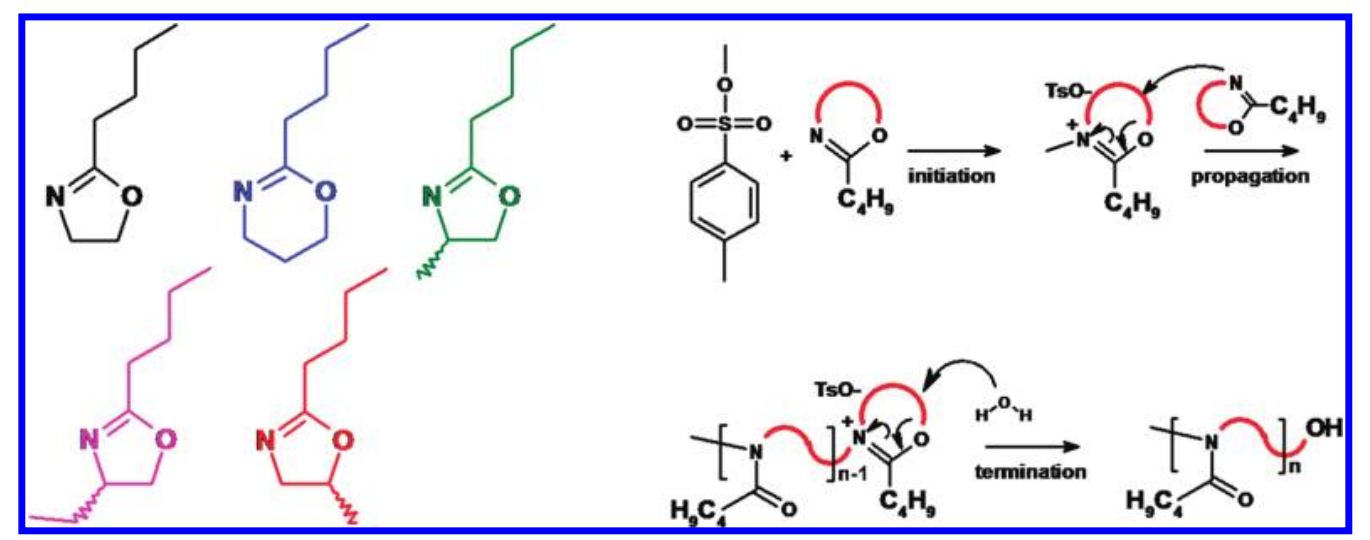

solvent. $\mathrm{MeOx}$ (Aldrich) and $\mathrm{PhOx}$ (Aldrich) were distilled over barium oxide and stored under argon. Methyl tosylate (Aldrich) was distilled without drying agent and stored under argon. Valeronitrile, 2-amino-1ethanol, 3-amino-1-propanol, 2-amino-1-propanol, 2-amino-1-butanol, 1-amino-2-propanol, and zinc acetate were obtained from Aldrich and used without further purification.

General Methods and Instrumentation. The polymerizations were performed under microwave irradiation with temperature control in the Emrys Liberator single-mode microwave synthesizer from Personal Chemistry (now Biotage) equipped with a noninvasive IR sensor (accuracy: $\pm 2 \%$ ). Microwave vials were heated to $110^{\circ} \mathrm{C}$ overnight and cooled to room temperature under argon before usage. Gas chromatography (GC) was measured on an Interscience Trace gas chromatograph with a Trace Column RTX-5 connected to a PAL autosampler. Size exclusion chromatography (SEC) measurements were performed on a Shimadzu system equipped with a SCL-10A system controller, a LC-10AD pump, a RID-10A refractive index detector, a SPD-10A UV-detector at $254 \mathrm{~nm}$ and a PLgel $5 \mu \mathrm{m}$ Mixed-D column at $50{ }^{\circ} \mathrm{C}$ utilizing a chloroform:triethylamine:2-propanol (94:4:2) mixture as eluent at a flow rate of $1 \mathrm{~mL} / \mathrm{min}$. The molar masses were calculated against polystyrene standards. ${ }^{1} \mathrm{H}$ NMR spectra of the products were recorded on a Varian AM-400 spectrometer at room temperature in $\mathrm{CDCl}_{3}$ as solvent. The chemical shifts are given in ppm relative to residual nondeuterated solvent signals. Thermal transitions were determined on a DSC 204 F1 Phoenix by Netzsch under a nitrogen atmosphere from -100 to $+220^{\circ} \mathrm{C}$ with a heating rate of $20 \mathrm{~K} / \mathrm{min}$ and a cooling rate of $40 \mathrm{~K} / \mathrm{min}$ (for the calculations, only the third heating curve of three runs was considered).

General Monomer Synthesis Procedure. The oxazoline monomers are all synthesized in a one-step reaction between valeronitrile and the corresponding aminoalcohol using zinc acetate as catalyst. $^{21,22}$ The aminoalcohol ( 1 mol equiv) was added dropwise to a mixture of the nitrile ( $1.1 \mathrm{~mol}$ equiv) and $\mathrm{Zn}(\mathrm{OAc})_{2}(0.02 \mathrm{~mol}$ equiv). After complete addition of the aminoalcohol the temperature was increased to $130{ }^{\circ} \mathrm{C}$. The reaction was kept under argon at $130{ }^{\circ} \mathrm{C}$ for 15 to $20 \mathrm{~h}$ followed by addition of dichloromethane. The resulting yellow suspension was washed with water ( 2 times) and brine ( 1 time). The separated organic layer was dried with magnesium sulfate, filtered and the solvent was evaporated under reduced pressure. The pure products where obtained as colorless liquids in $50-70 \%$ yield after vacuum distillation with barium oxide.

2-Butyl-2-oxazoline. ${ }^{1} \mathrm{H}$ NMR $\left(\mathrm{CDCl}_{3}\right): \delta 4.21(\mathrm{t}, J=9.5 \mathrm{~Hz}, 2 \mathrm{H}$, $\left.\mathrm{OCH}_{2}\right), 3.82\left(\mathrm{t}, J=9.5 \mathrm{~Hz}, 2 \mathrm{H}, \mathrm{NCH}_{2}\right), 2.72(\mathrm{t}, J=7.7 \mathrm{~Hz}, 2 \mathrm{H}$, $\mathrm{CCH}_{2}$ ), 1,62 (quintet, $J=7.8 \mathrm{~Hz}, 2 \mathrm{H}, \mathrm{CCH}_{2} \mathrm{CH}_{2}$ ), 1.37 (sextet, $J=$ $\left.7.8 \mathrm{~Hz}, 2 \mathrm{H}, \mathrm{CCH}_{2} \mathrm{CH}_{2} \mathrm{CH}_{2}\right), 0.92\left(\mathrm{t}, J=7.2 \mathrm{~Hz}, 3 \mathrm{H}, \mathrm{CH}_{3}\right), \mathrm{GC}-\mathrm{MS}$ : $\mathrm{M}^{+}=126(100 \%)$.
2-Butyl-2-oxazine. ${ }^{1} \mathrm{H}$ NMR $\left(\mathrm{CDCl}_{3}\right): \delta 4.15(\mathrm{t}, J=5.2 \mathrm{~Hz}, 2 \mathrm{H}$, $\left.\mathrm{OCH}_{2}\right), 3.36(\mathrm{t}, J=5.8 \mathrm{~Hz}, 2 \mathrm{H}, \mathrm{NCH}), 2.13\left(\mathrm{t}, J=7.7 \mathrm{~Hz}, 2 \mathrm{H}, \mathrm{CCH}_{2}\right)$, $1.85\left(\mathrm{t}, J=5.8 \mathrm{~Hz}, 2 \mathrm{H}, \mathrm{OCH}_{2} \mathrm{CH}_{2}\right), 1.55$ (quintet, $J=7.3 \mathrm{~Hz}, 2 \mathrm{H}$, $\mathrm{CCH}_{2} \mathrm{CH}_{2}$ ), 1.35 (sextet, $\left.J=7.3 \mathrm{~Hz}, 2 \mathrm{H}, \mathrm{CCH}_{2} \mathrm{CH}_{2} \mathrm{CH}_{2}\right), 0.91(\mathrm{t}, J=$ $\left.7.2 \mathrm{~Hz}, 3 \mathrm{H}, \mathrm{CH}_{3}\right), \mathrm{GC}-\mathrm{MS}: \mathrm{M}^{+}=140(100 \%)$.

RS-4-Methyl-2-butyl-2-oxazoline. ${ }^{1} \mathrm{H}$ NMR $\left(\mathrm{CDCl}_{3}\right): \delta 4.27(\mathrm{t}, J=$ $8.6 \mathrm{~Hz}, 1 \mathrm{H}, \mathrm{OCH}), 4.10$ (sextet, $J=6.8 \mathrm{~Hz}, 1 \mathrm{H}, \mathrm{NCH}), 3.705(\mathrm{t}, J=7.8$ $\mathrm{Hz}, 1 \mathrm{H}, \mathrm{OCH}$ ), $2.23\left(\mathrm{t}, J=7.1 \mathrm{~Hz}, 2 \mathrm{H}, \mathrm{CCH}_{2}\right.$ ), 1.58 (quintet, $J=7.1 \mathrm{~Hz}$, $2 \mathrm{H}, \mathrm{CCH}_{2} \mathrm{CH}_{2}$ ), 1.33 (sextet, $J=7.1 \mathrm{~Hz}, 2 \mathrm{H}, \mathrm{CCH}_{2} \mathrm{CH}_{2} \mathrm{CH}_{2}$ ), 1.21 $\left(\mathrm{d}, J=7.1 \mathrm{~Hz}, 3 \mathrm{H}, \mathrm{NCHCH}_{3}\right), 0.89\left(\mathrm{t}, J=7.3 \mathrm{~Hz}, 3 \mathrm{H}, \mathrm{CH}_{3}\right), \mathrm{GC}-\mathrm{MS}$ : $\mathrm{M}^{+}=140(100 \%)$.

$R S$-4-Ethyl-2-butyl-2-oxazoline. ${ }^{1} \mathrm{H}$ NMR $\left(\mathrm{CDCl}_{3}\right): \delta 4.26(\mathrm{t}, J=8.0$ $\mathrm{Hz}, 1 \mathrm{H}, \mathrm{OCH}$ ), 4.01 (quintet, $J=7.1 \mathrm{~Hz}, 1 \mathrm{H}, \mathrm{NCH}$ ), 3.84 (t, $J=7.6$ $\mathrm{Hz}, 1 \mathrm{H}, \mathrm{OCH}), 2.27\left(\mathrm{t}, J=7.8 \mathrm{~Hz}, 2 \mathrm{H}, \mathrm{CCH}_{2}\right), 1.67-1.45(\mathrm{~m}, J=7.1$ $\mathrm{Hz}, 4 \mathrm{H}, \mathrm{CCH}_{2} \mathrm{CH}_{2}$ and $\left.\mathrm{OCH} \mathrm{CH} \mathrm{CH}_{2}\right), 1.37$ (sextet, $J=7.4 \mathrm{~Hz}, 2 \mathrm{H}$, $\left.\mathrm{CCH}_{2} \mathrm{CH}_{2} \mathrm{CH}_{2}\right), 0.96-0.90\left(\mathrm{~m}, J=7.6 \mathrm{~Hz}, 6 \mathrm{H}, 2 \mathrm{CH}_{3}\right), \mathrm{GC}-\mathrm{MS}$ : $\mathrm{M}^{+}=154(100 \%)$.

RS-5-Methyl-2-butyl-2-oxazoline. ${ }^{1} \mathrm{H}$ NMR $\left(\mathrm{CDCl}_{3}\right): \delta 4.57(\mathrm{~m}$, $1 \mathrm{H}, \mathrm{OCH}), 4.05\left(\mathrm{~m}, 2 \mathrm{H}, \mathrm{NCH}_{2}\right), 2.25\left(\mathrm{t}, J=7.1 \mathrm{~Hz}, 2 \mathrm{H}, \mathrm{CCH}_{2}\right), 1.79$ $\left(\mathrm{d}, J=7.1 \mathrm{~Hz}, 3 \mathrm{H}, \mathrm{OCHCH}_{3}\right.$ ), 1.56 (quintet, $J=7.1 \mathrm{~Hz}, 2 \mathrm{H}, \mathrm{CCH}_{2} \mathrm{CH}_{2}$ ), 1.35 (sextet, $J=7.1 \mathrm{~Hz}, 2 \mathrm{H}, \mathrm{CCH}_{2} \mathrm{CH}_{2} \mathrm{CH}_{2}$ ), $0.90(\mathrm{t}, J=7.1 \mathrm{~Hz}, 3 \mathrm{H}$, $\left.\mathrm{CH}_{3}\right), \mathrm{GC}-\mathrm{MS}: \mathrm{M}^{+}=140(100 \%)$.

Kinetic Investigations on the Microwave-Assisted Polymerizations. The polymerization kinetics were studied by preparing first a stock solution of the monomer with $4 \mathrm{M}$ concentration in acetonitrile together with methyl tosylate resulting in a monomer to initiator ratio of 60 . This stock solution was divided over several microwave vials ( $1 \mathrm{~mL}$ each) that were heated for different predefined times to $140^{\circ} \mathrm{C}$. After microwave heating, the polymerization mixture was cooled to $38^{\circ} \mathrm{C}$ and quenched by the addition of water. GC and SEC samples were prepared from the polymerization mixtures to determine the monomer conversion and the molar mass (distribution) of the resulting polymers. The monomer conversion was calculated from integration of the GC signals, whereby the solvent signal was used as internal standard.

The copolymerization kinetics were determined in a similar manner using a total monomer to initiator ratio of 100 with $\left[\mathrm{M}_{1}\right]=\left[\mathrm{M}_{2}\right]$ for two monomers or $\left[\mathrm{M}_{1}\right]=\left[\mathrm{M}_{2}\right]=\left[\mathrm{M}_{3}\right]$ for three monomers.

\section{RESULTS AND DISCUSSION}

The investigated cyclic imino ethers were prepared by a condensation reaction between valeronitrile and the corresponding amino-alcohols using zinc acetate as catalyst. ${ }^{20,21}$ All monomers were prepared bearing a butyl-group on the two position to 
exclude side-group effects on the polymerization behavior. ${ }^{23}$ The synthesized cyclic imino ether monomers are 2-butyl-2-oxazoline, 2-butyl-2-oxazine, 4-methyl-2-butyl-2-oxazoline, 4-ethyl-2butyl-2-oxazoline, and 5-methyl-2-butyl-2-oxazoline, whereby the latter three are racemic mixtures. ${ }^{24}$

The cationic ring-opening polymerization of these cyclic imino ethers was investigated using our previously determined optimal reaction conditions for 2-oxazolines, namely polymerization with methyl tosylate as initiator in acetonitrile at $140{ }^{\circ} \mathrm{C}$ using a monomer concentration of $4 \mathrm{M}$ and a monomer to initiator ratio of $60{ }^{14,15}$ Upon heating the polymerization mixture, nucleophilic attack of the cyclic imino ether onto the methyl tosylate results in the formation of a cationic propagating species having a weakened $\mathrm{C}-\mathrm{O}$ bond. Subsequent attack of the next monomer onto this carbon atom yields the ring-opened poly(cyclic imino ether) still bearing the reactive cationic group. At the end of the polymerization, the living chain ends were quenched by the addition of water resulting in a mixture of hydroxy and ester end-groups due to water addition to the 2- and 5 -positions of the propagating species. ${ }^{25,26}$ This general polymerization mechanism is shown in Scheme 1.

The polymerization kinetics were determined by polymerizing separate samples of the polymerization mixture for different times under microwave irradiation. The resulting mixtures were analyzed by gas chromatography (GC) to determine the monomer conversion as well as by size exclusion chromatography (SEC) to determine the molar mass and molar mass distribution of the polymers. The living CROP of 2-oxazolines is known to follow first order kinetics based on the constant concentration of cationic propagating species. When plotting the conversion data in a first order kinetic plot $\left(\ln \left([\mathrm{M}]_{0} /[\mathrm{M}]_{\mathrm{t}}\right)\right.$ versus time $)$ a linear correlation was found for all investigated monomers confirming that the polymerizations followed first order kinetics (Figure 1). In addition, the linear increase of the number-average molar mass $\left(M_{\mathrm{n}}\right)$ with conversion together with the relatively low polydispersity indices (PDI < 1.35) indicate that the polymerizations were controlled; although the PDI values indicate the occurrence of some chain transfer side reactions. For most monomers, the intercept of the molar mass versus conversion plots is rather high, which can be ascribed to the relative molar mass determination against polystyrene standards. The only exception is the polymerization of 4-methyl-2-butyl-2-oxazoline that resulted in polymers with broader molar mass distributions (PDI > 1.4) and rather low $M_{\mathrm{n}}$ values most likely resulting from a larger extent of chain transfer reactions presumably caused by impurities in the monomer or trace amounts of water. The lower purity of this monomer is caused by the smaller scale synthesis $(<5 \mathrm{~mL})$ complicating the work-up and purification procedures.

The polymerization rate constants $\left(k_{\mathrm{p}}\right)$ for the different cyclic imino ethers were calculated from the slope of the first order kinetic plots assuming complete initiation and absence of termination (chain transfer will not affect the polymerization rate) and the values are summarized in Table 1 . The assumption of complete initiation is confirmed by the ${ }^{1} \mathrm{H}$ NMR spectra of the polymerization mixtures revealing a complete shift, already for the first kinetic samples, of the aromatic signals from 7.35 and $7.80 \mathrm{ppm}$ for the methyl tosylate to 7.16 and $7.74 \mathrm{ppm}$ for the anionic tosylate counterion (data not shown). The polymerization of 2-butyl-2-oxazoline revealed the highest $k_{\mathrm{p}}$, which is similar to the values reported for other 2-n-alkyl-2-oxazolines. ${ }^{25}$ Expanding the ring size to the 2-butyl-2-oxazine lowers the polymerization rate, which can be ascribed to the increased

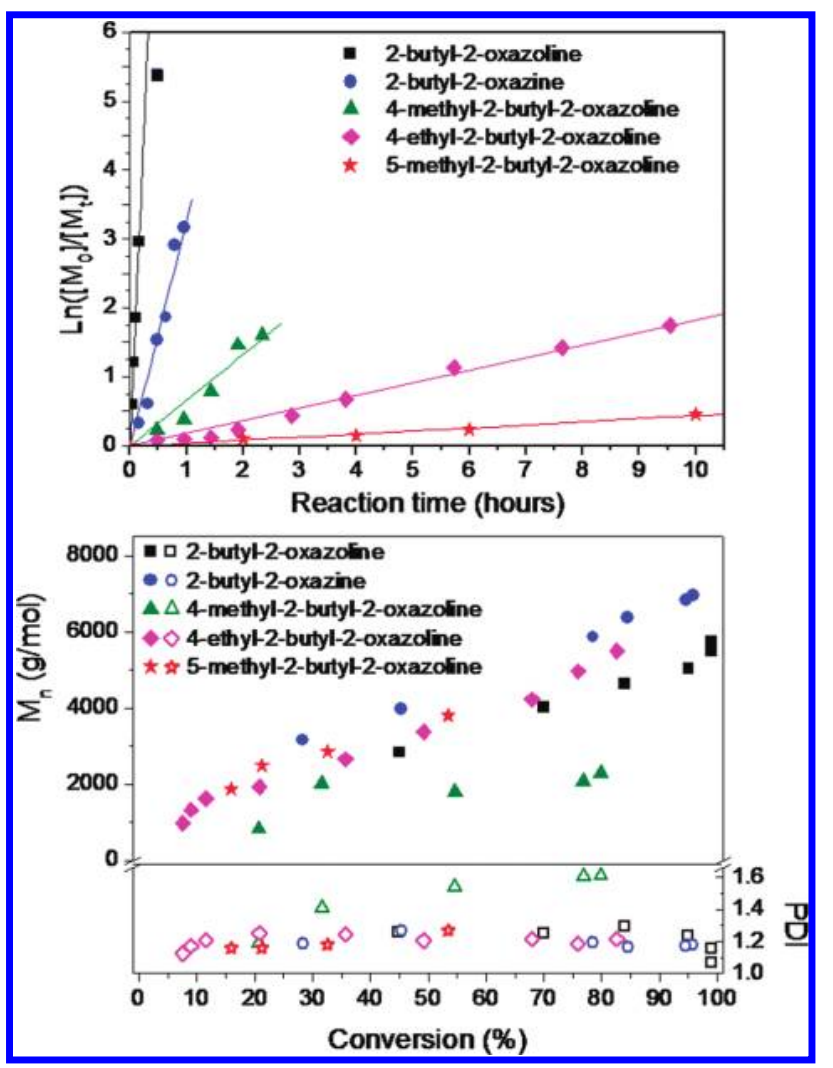

Figure 1. Top: First order kinetic plot for the cationic ring-opening polymerization of the cyclic imino ethers. Bottom: Evolution of numberaverage molar mass $\left(M_{n}\right)$ and polydispersity index (PDI) with conversion. Microwave polymerizations performed at $140{ }^{\circ} \mathrm{C}$ in acetonitrile using methyl tosylate as initiator, $[\mathrm{M}] /[\mathrm{I}]=60$ and $[\mathrm{M}]=4 \mathrm{M}$. SEC analysis was performed with $\mathrm{CHCl}_{3}$ : 2-propanol:triethylamine (94:2:4) mixture as eluent and a polystyrene calibration.

sterical hindrance for nucleophilic monomer addition resulting from the gauche conformation of the nonplanar oxazonium ring compared to the flat oxazolinium species. ${ }^{27}$ Nonetheless, complete monomer conversion is still reached within $1 \mathrm{~h}$ for the CROP of 2-butyl-2-oxazine. Substitution of the oxazoline ring has a much more drastic effect on the polymerization rate leading to an almost 30-fold decrease in $k_{\mathrm{p}}$ for 4-methyl-2-butyl-2oxazoline compared to 2-butyl-2-oxazoline. This slower polymerization can be ascribed to increased sterical hindrance for the attack of the next monomer as is clearly evidenced by the additional 3-fold decrease in $k_{\mathrm{p}}$ when changing the 4-substituent from methyl to ethyl giving 4-ethyl-2-butyl-2-oxazoline. Placing a methyl substituent on the 5-position, i.e., where the next monomer will attack, resulting in 5-methyl-2-butyl-2-oxazoline results in the slowest polymerizing cyclic imino ether among the studied variants, which again can be ascribed to increased sterical hindrance. Even though the $k_{\mathrm{p}}$ is drastically lowered by incorporating 4- and 5-substituents, the microwave-assisted polymerization procedure still enables reasonable monomer conversion of at least 50\% for the slowest 5-methyl-2-butyl-2-oxazoline cyclic imino ether within $10 \mathrm{~h}$ polymerization time.

The effect of the cyclic imino ether structure on the thermal properties of the resulting polymers was evaluated based on differential scanning calorimetry (DSC) measurements. The glass transition temperatures $\left(T_{\mathrm{g}}\right)$ noticeably demonstrate that increasing the ring size leads to enhanced chain flexibility and, 
Table 1. Polymerization Rate Constants $\left(k_{\mathrm{p}}\right)$ of the Cyclic Imino Ethers and Glass Transitions Temperatures ( $\left.T_{\mathrm{g}}\right)$ of the Resulting Polymers

\begin{tabular}{|c|c|c|c|c|c|}
\hline monomer & $k_{\mathrm{p}}{ }^{a}$ & $T_{\mathrm{g}}{ }^{b}{ }^{\circ} \mathrm{C}$ & monomer & $k_{\mathrm{p}}{ }^{a}$ & $T_{\mathrm{g}}{ }^{b}{ }^{\circ} \mathrm{C}$ \\
\hline 2-butyl-2-oxazoline & $139 \pm 2$ & 23.8 & 4-methyl-2-butyl-2-oxazoline & $5.0 \pm 0.4$ & 51.3 \\
\hline 2-butyl-2-oxazine & $22.2 \pm 1.5$ & -5.1 & 4-ethyl-2-butyl-2-oxazoline & $1.6 \pm 0.1$ & 58.8 \\
\hline & & & 5-methyl-2-butyl-2-oxazoline & $0.32 \pm 0.03$ & 34.0 \\
\hline
\end{tabular}

${ }^{a}$ In $10^{-3} \mathrm{~L} /(\mathrm{mol} \times \mathrm{s})$; Calculated from the slope of the first order kinetic plots. ${ }^{b}$ Determined by differential scanning calorimetry with a heating rate of $20 \mathrm{~K} / \mathrm{min}$.

thus, a lower $T_{\mathrm{g}}$ (Table 1$)$. In contrast, adding substituents to the 4- and 5-position of the 2-oxazoline ring enhances the rigidity of the resulting polymers bearing main-chain substituents leading to an increase in $T_{\mathrm{g}}$. The unexpectedly low $T_{\mathrm{g}}$ for poly (5-methyl-2butyl-2-oxazoline) might be related to the low 50\% monomer conversion of the final kinetic sample that was used for analysis, i.e., the fraction of flexible chain ends is higher resulting in a lower $T_{\mathrm{g}}$ and/or a minor fraction of residual monomer might act as plasticizer.

Recently, we demonstrated the one-pot quasi-diblock copolymer synthesis based on the large difference in reactivity of 2-methyl-2-oxazoline $\left(k_{\mathrm{p}}=145 \times 10^{-3} \mathrm{~L} /(\mathrm{mol} \times \mathrm{s})\right.$ at $\left.140{ }^{\circ} \mathrm{C}\right)^{25}$ and 2-phenyl-2-oxazoline $\left(k_{\mathrm{p}}=32 \times 10^{-3} \mathrm{~L} /(\mathrm{mol} \times \mathrm{s})\right.$ at $\left.140{ }^{\circ} \mathrm{C}\right) .{ }^{15,28}$ On the basis of the even slower, but still controlled, polymerization found for 4-ethyl-2-butyl-2-oxazoline it was anticipated that the one-pot copolymerization of 2-methyl2-oxazoline, 2-phenyl-2-oxazoline and 4-ethyl-2-butyl-2-oxazoline at $140{ }^{\circ} \mathrm{C}$ would lead to the formation of a quasi-triblock copolymer structure. However, kinetic analysis of this copolymerization surprisingly revealed the formation of a gradient copolymer structure going from a 2-methyl-2-oxazoline rich domain, via a 4-ethyl-2-butyl-2-oxazoline rich domain to a 2-phenyl-2-oxazoline rich domain at the final stages of the polymerization (Figure 2, bottom).

Unfortunately, ${ }^{1} \mathrm{H}$ NMR spectroscopy could not be used to analyze the copolymer composition due to the very broad signals of the poly(4-ethyl-2-butyl-2-oxazoline) $(2.0-4.5 \mathrm{ppm})$ resulting in significant overlap. Nonetheless, the almost complete monomer conversions (complete conversion of 2-methyl-2oxazoline and 4-ethyl-2-butyl-2-oxazoline; 75\% conversion of 2-phenyl-2-oxazoline) in combination with a polydispersity index below 1.30 indicate that the copolymer has the expected composition.

To better understand the unexpected copolymer behavior, the copolymerization of the separate monomer pairs were also studied. Statistical copolymerization of 2-methyl-2-oxazoline with 4-ethyl-2-butyl-2-oxazoline revealed the expected fast incorporation of 2-methyl-2-oxazoline resulting in a quasi-diblock copolymer structure. However, the calculated $k_{\mathrm{p}}$ of $60 \pm 3 \times$ $10^{-3} \mathrm{~L} /(\mathrm{mol} \times \mathrm{s})$ for $\mathrm{MeOx}$ indicates a deceleration in the presence of 4-ethyl-2-butyl-2-oxazoline (Figure 2, top). The first order kinetic plot for 4-ethyl-2-butyl-2-oxazoline revealed two regimes with an initial $k_{\mathrm{p}}$ of $(7.7 \pm 0.3) \times 10^{-3} \mathrm{~L} /(\mathrm{mol} \times \mathrm{s})$ and a $k_{\mathrm{p}}$ of $(2.2 \pm 0.2) \times 10^{-3} \mathrm{~L} /(\mathrm{mol} \times \mathrm{s})$ during the later stages of the polymerization. This later $k_{\mathrm{p}}$ is observed when all 2-methyl-2oxazoline has been consumed and resembles the $k_{\mathrm{p}}$ obtained for the homopolymerization of 4-ethyl-2-butyl-2-oxazoline. The enhanced $k_{\mathrm{p}}$ for 4-ethyl-2-butyl-2-oxazoline in combination with the decreased $k_{\mathrm{p}}$ for 2-methyl-2-oxazoline when both monomers are present indicate a nonideal copolymerization behavior, whereby the higher accessibility of the 2-methyl-2-oxazolinium propagating species accelerate the incorporation of 4-ethyl-2butyl-2-oxazoline compared to its homopolymerization while the polymerization of 2-methyl-2-oxazoline is slowed down compared to its homopolymerization due to the higher sterical hindrance of the 4-ethyl-2-butyl-2-oxazolinium propagating species.

The statistical copolymerization of 4-ethyl-2-butyl-2-oxazoline with 2-phenyl-2-oxazoline, surprisingly, revealed a faster incorporation of 4-ethyl-2-butyl-2-oxazoline $\left(k_{\mathrm{p}}\right.$ of $(3.8 \pm 0.3) \times$ $\left.10^{-3} \mathrm{~L} /(\mathrm{mol} \times \mathrm{s})\right)$ than 2-phenyl-2-oxazoline $\left(k_{\mathrm{p}}\right.$ of $(1.5 \pm 0.1) \times$ $\left.10^{-3} \mathrm{~L} /(\mathrm{mol} \times \mathrm{s})\right)$ resulting in a monomer gradient from 4-ethyl-2-butyl-2-oxazoline to 2-phenyl-2-oxazoline, despite the 20-fold faster homopolymerization of 2-phenyl-2-oxazoline compared to 4-ethyl-2-butyl-2-oxazoline (Figure 2, middle). This large discrepancy can be ascribed to the large aromatic side-chain of 2-phenyl-2-oxazoline, which amplifies the sterical hindrance for attack onto 4-ethyl-2-butyl-2-oxazoline oxazolinium propagating species. In contrast, the attack of 4-ethyl-2-butyl-2-oxazoline onto 2-phenyl-2-oxazolinium is more efficient compared to the attack on the more sterically hindered C-5 of 4-ethyl-2-butyl2-oxazolinium species. When analyzing the terpolymerizations kinetics in more detail, keeping the copolymerization results in mind, it can be calculated that the polymerization of 2-methyl-2oxazoline is slower $\left(k_{\mathrm{p}}\right.$ of $\left.(86 \pm 4) \times 10^{-3} \mathrm{~L} /(\mathrm{mol} \times \mathrm{s})\right)$ compared to its homopolymerization, but faster compared to the copolymerization with 4-ethyl-2-butyl-2-oxazoline. In addition, the kinetics of 4-ethyl-2-butyl-2-oxazoline also revealed two slopes in the terpolymerizations; a $k_{\mathrm{p}}$ of $(13.7 \pm 0.3) \times 10^{-3}$ $\mathrm{L} /(\mathrm{mol} \times \mathrm{s})$ in the presence of 2 -methyl-2-oxazoline, which decreases to $(6.5 \pm 0.3) \times 10^{-3} \mathrm{~L} /(\mathrm{mol} \times \mathrm{s})$ after full conversion of 2-methyl-2-oxazoline. Finally, the $k_{\mathrm{p}}$ for 2-phenyl-2-oxazoline was found to be $(3.1 \pm 0.2) \times 10^{-3} \mathrm{~L} /(\mathrm{mol} \times \mathrm{s})$ in the terpolymerizations. These observed trends for the terpolymerization are similar to the copolymerizations. Nonetheless, all $k_{\mathrm{p}}$ values calculated for the terpolymerizations are higher than for the copolymerizations, which can be ascribed to the lower amount of the more sterically hindered 4-ethyl-2-butyl-2-oxazoline monomer in the terpolymerizations (33\% in the terpolymerizations versus $50 \%$ for the copolymerizations).

The contribution of preferential microwave heating of the 4-ethyl-4-butyl-2-oxazoline as driving force for the unexpected copolymerization kinetics can be ruled out based on the following discussion. In our previous work we have shown for the homopolymerization of 2-ethyl-2-oxazoline and 2-phenyl-2-oxazoline, i.e., two very different 2 -oxazoline monomers, that the observed acceleration under similar microwave-assisted polymerization conditions was solely due to the increased temperatures facilitated by the closed vial conditions. ${ }^{14,18}$ Therefore, it is expected that this absence of a nonthermal microwave effect can be extrapolated to 4-ethyl-2-butyl-2-oxazoline, which structure is rather similar to 2-ethyl-2-oxazoline. This assumption is further justified by the fact that the solvent, acetonitrile, also 

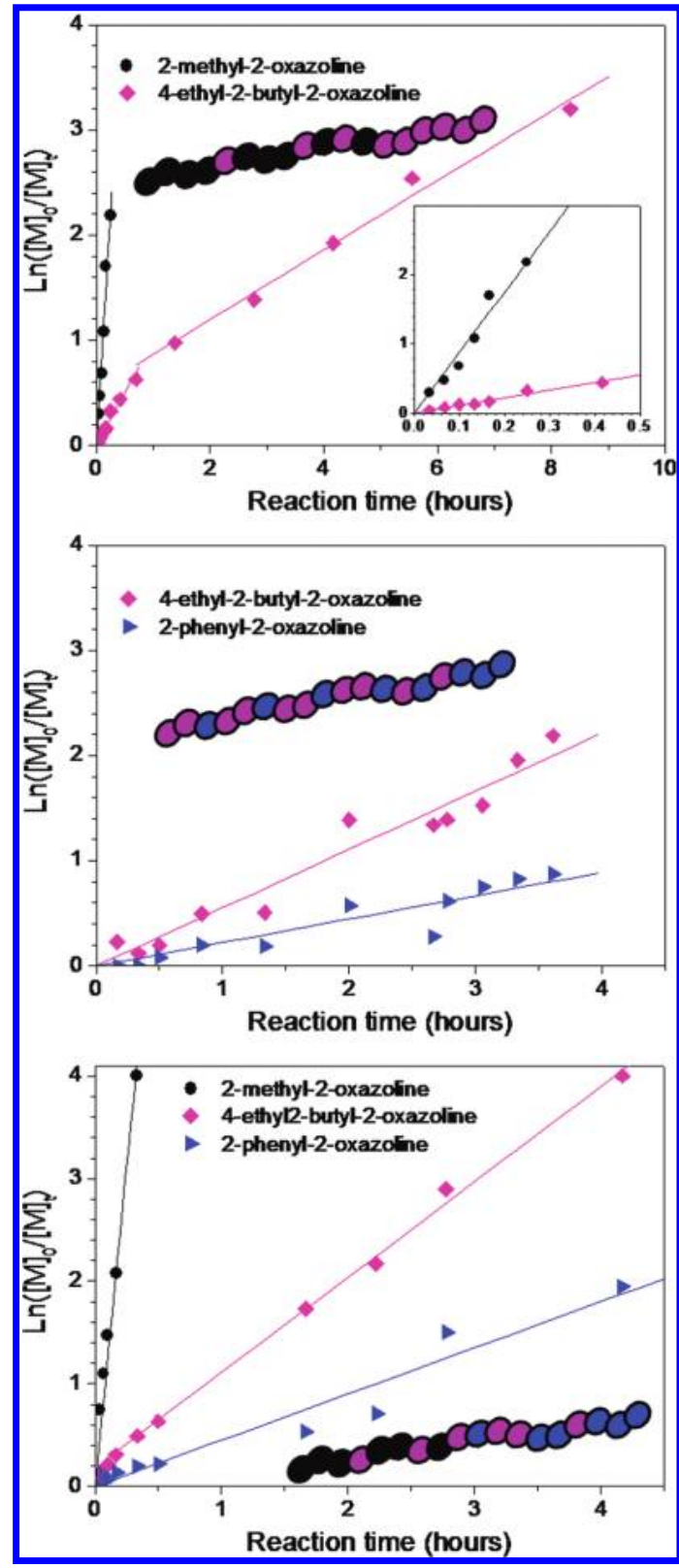

Figure 2. First order kinetic plots for the cationic ring-opening copolymerization of 2-methyl-2-oxazoline and/or 2-phenyl-2-oxazoline with 4-ethyl-2-butyl-2-oxazoline. The depicted polymer structures represent the calculated monomer order. Microwave polymerizations were performed at $140{ }^{\circ} \mathrm{C}$ in acetonitrile using methyl tosylate as initiator, $[\mathrm{M}]_{\text {total }} /[\mathrm{I}]=100$ and $[\mathrm{M}]_{\text {tot }}=4 \mathrm{M}$.

efficiently absorbs microwaves suppressing any potential preferential microwave absorbance of the monomer. Finally, in recent years, the majority of the microwave community has reached consensus that nonthermal microwave effects do not exist for homogeneous reactions in solution. ${ }^{29,30}$

\section{CONCLUSIONS}

In conclusion, the microwave-assisted polymerization of various cyclic imino ethers is reported revealing a decrease in polymerization rate constant due to increased sterical hindrance in the following order: 2-butyl-2-oxazoline $>2$-butyl-2-oxazine $>$ 4-methyl-2-butyl-2-oxazoline > 4-ethyl-2-butyl-2-oxazoline > 5-methyl-2-butyl-2-oxazoline. All microwave-assisted polymerizations could be performed in a controlled manner, although significant chain transfer side reactions were observed for 4-methyl-2-butyl-2-oxazoline presumably due to minor impurities, such as traces of water. Statistical copolymerization of 2-methyl-2-oxazoline, 2-phenyl-2-oxazoline and 4-ethyl-2butyl-2-oxazoline revealed that the polymerization of 4-ethyl-2butyl-2-oxazoline is accelerated due to the better accessibility of the oxazolinium species without 4-substituents. In contrast, the polymerization of 2-methyl-2-oxazoline and 2-phenyl-2-oxazoline are slowed down by the presence of the more sterically hindered 4-ethyl-2-butyl-2-oxazolinium species. This effect is amplified by the large size of the aromatic side group of 2-phenyl-2-oxazoline resulting in a faster incorporation of 4-ethyl-2-butyl-2-oxazoline compared to 2-phenyl-2-oxazoline during the statistical copolymerization while, in contrast, 2-phenyl-2oxazoline exhibits a faster homopolymerization.

These results provide important new insights into the polymerization behavior of cyclic imino ethers opening up new possibilities for their more widespread use as comonomers during CROP of 2-oxazolines. Moreover, the fast microwaveassisted polymerization procedure enables efficient polymerization of 4- and 5-substituted 2-oxazolines.

\section{AUTHOR INFORMATION}

\section{Corresponding Author}

*E-mail: ulrich.schubert@uni-jena.de (U.S.S.) or richard. hoogenboom@ugent.be (R.H.).

\section{ACKNOWLEDGMENT}

The authors thank the Dutch Polymer Institute (DPI, technology area HTE) and NWO (VICI award for U.S.S. and VENI award for R.H.) for financial support.

\section{REFERENCES}

(1) Litt, M. H.; Levy, A. J.; Bassiri, T. G. BE666828, 1965; US3483141.

(2) Tomalia, D. A.; Sheetz, D. P. J. Polym. Sci., Part A: Polym. Chem. 1966, 4, 2253-2265.

(3) Seeliger, W.; Aufderhaar, E.; Diepers, W.; Feinauer, R; Nehring, R.; Thier, W.; Hellmann, H. Angew. Chem., Int. Ed. Engl. 1966, 20, 913-927.

(4) Kagiya, T.; Narisawa, S.; Maeda, T.; Fukui, K. J. Polym. Sci., Part B: Polvm. Lett. 1966, 4, 441-445.

(5) Bassiri, T. G.; Levy, A.; Litt, M. J. Polym. Sci., Part B: Polym. Lett. 1967, 5, 871-879.

(6) Levy, A.; Litt, M. J. Polym. Sci., Part B: Polym. Lett. 1967, 5, 881-886.

(7) Saegusa, T.; Kobayashi, S.; Ishiguro, M. Macromolecules 1974, 7, 958-959.

(8) Saegusa, T.; Hirao, T.; Ito, Y. Macromol. Commun. 1975, 8, 87.

(9) Kobayashi, S.; Uyama, H. Polvm. I. 1991, 23, 1015-1017.

(10) Aoi, K.; Okada, M. Proo. Polvm. Sci. 1996, 21, 151-208.

(11) Adams, N.; Schubert, U. S. Adv. Drug Delivery Rev. 2007, $59,1504-1520$.

(12) Hoogenboom, R. Angew. Chem. Int. Ed. 2009, 48, 7978-7994.

(13) Schlaad, H.; Diehl, C.; Gress, A.; Meyer, M.; Demirel, A. L.;

Nur, Y.; Bertin, A. Macromol. Rapid Commun. 2010, 31, 511-525.

(14) Wiesbrock, F.; Hoogenboom, R.; Abeln, C. A.; Schubert, U. S. Macromol. Rapid Commun. 2004, 25, 1895-1899.

(15) Wiesbrock, F.; Hoogenboom, R.; Leenen, M. A. M.; Meier, M. A. R.; Schubert, U. S. Macromolecules 2005, 38, 5025-5034. 
(16) Sinnwell, S.; Ritter, H. Macromol. Rapid Commun. 2005, 26, $160-163$.

(17) Luxenhofer, R.; Jordan, R. Macromolecules 2006, 39, 3509-3516.

(18) Hoogenboom, R.; Fijten, M. W. M.; Paulus, R. M.; Thijs, H. M. L.; Hoeppener, S.; Kickelbick, G.; Schubert, U. S. Polymer 2006, $47,75-84$

(19) Sinnwell, S.; Ritter, H. Macromol. Rapid Commun. 2006, 27, $1335-1340$.

(20) Bloksma, M. M.; Rogers, S.; Schubert, U. S.; Hoogenboom, R. Soft Matter 2010, 6, 994-1003.

(21) Witte, H.; Seeliger, W. Liebigs Ann. Chem. 1974, 996-1009.

(22) Kempe, K.; Lobert, M.; Hoogenboom, R.; Schubert, U. S. I. Comb. Chem. 2009, 11, 274-280.

(23) The butyl side-chain on the 2-position also simplifies monomer purification by distillation, compared to monomers with smaller side chains, which are very volatile resulting in larger losses.

(24) For the synthesis, polymerization and secondary structure formation of chiral 4-ethyl-2-butyl-2-oxazoline monomers see ref 19 and Bloksma, M. M.; Hendrix, M. M. R. M.; Schubert, U. S.; Hoogenboom, R. Macromolecules 2010, 43, 4654-4659.

(25) Nuyken, O.; Maier, G.; Gross, A. Macromol. Chem. Phys. 1996, 197, 83-95.

(26) Hoogenboom, R.; Fijten, M. W. M.; Thijs, H. M. L.; Van Lankvelt, B. M.; Schubert, U. S. Des. Monomers Polvm. 2005, 8, 659-671.

(27) Saegusa, T.; Kobayashi, S.; Nagura, Y. Macromolecules 1974, $7,265-272$.

(28) Hoogenboom, R.; Thijs, H. M. L.; Fijten, M. W. M.; Van Lankvelt, B. M.; Schubert, U. S. J. Polym. Sci., Part A: Polym. Chem. 2007, $45,416-422$.

(29) Obermayer, D.; Gutmann, D.; Kappe, C. O. Angew. Chem., Int. Ed. 2009, 48, 8321-8324.

(30) De Cózar, A.; Millán, M. C.; Cebrián, C.; Prieto, P.; Díaz-Ortiz, A.; De la Hoz, A.; Cossío, F. P. Org. Biomol. Chem. 2010, 8, 1000-1009. 